\title{
The Infrared Spectrum of Protonated $\mathrm{C}_{\mathbf{7 0}}$
}

\author{
Julianna Palotás $^{1}$, Jonathan Martens ${ }^{1}$ (D) , Giel Berden ${ }^{1}$ (D), and Jos Oomens ${ }^{1,2}$ (D) \\ ${ }^{1}$ Radboud University, Institute for Molecules and Materials, FELIX Laboratory, Toernooiveld 7, 6525 ED Nijmegen, The Netherlands; jos.oomens@ru.nl \\ 2 van 't Hoff Institute for Molecular Sciences, University of Amsterdam, Science Park 908, 1098 XH Amsterdam, The Netherlands \\ Received 2020 December 3; revised 2021 February 4; accepted 2021 February 15; published 2021 March 10
}

\begin{abstract}
With the detection of $\mathrm{C}_{60}, \mathrm{C}_{70}$, and $\mathrm{C}_{60}^{+}$in the interstellar medium, fullerenes are currently the largest molecules identified in space. The relatively high proton affinities of $\mathrm{C}_{60}$ and $\mathrm{C}_{70}$ support the hypothesis that protonated fullerenes may also be abundant in the interstellar matter. Here, we present the first experimental vibrational spectrum of $\mathrm{C}_{70} \mathrm{H}^{+}$, recorded in the gas phase. The attachment of a proton to $\mathrm{C}_{70}$ causes a drastic symmetry lowering, which results in a rich vibrational spectrum. As compared to $\mathrm{C}_{60}$, where all $\mathrm{C}$-atoms are equivalent due to the icosahedral symmetry, $C_{70}$ belongs to the $D_{5 h}$ point group and has five nonequivalent $C$-atoms, which are available as protonation sites. Combined analysis of the experimental spectrum and spectra computed at the density functional theory level enables us to evaluate the protonation isomers being formed. We compare the IR spectra of $\mathrm{C}_{60} \mathrm{H}^{+}$and $\mathrm{C}_{70} \mathrm{H}^{+}$to IR emission spectra from planetary nebulae, which suggests that a mixture of these fullerene analogs could contribute to their IR emission.
\end{abstract}

Unified Astronomy Thesaurus concepts: Molecular spectroscopy (2095); Laboratory astrophysics (2004); Interstellar medium (847)

Supporting material: machine-readable table

\section{Introduction}

Like its carbonaceous sibling $\mathrm{C}_{60}$, the $\mathrm{C}_{70}$ molecule has received much attention as the next most abundant member of the fullerene family. Similar to $\mathrm{C}_{60}$, it follows the isolated pentagon rule that makes this allotrope of carbon particularly stable (Kroto 1987; Fowler 1996). Upon their discovery in the 1980s, both fullerenes attracted the attention of the astrophysical community and initiated a search for their presence in interstellar environments (Ehrenfreund \& Foing 1997). As predicted already at the time of their discovery (Kroto et al. 1985; Krätschmer et al. $1990), C_{70}$, together with $C_{60}$ have now been detected in various astronomical objects (Cami et al. 2010; García-Hernández et al. 2010, 2011, 2012; Sellgren et al. 2010; Iglesias-Groth 2019). Based on accurate gas-phase laboratory spectra in the near-IR, $\mathrm{C}_{60}^{+}$ was more recently identified (Campbell et al. 2015), representing a rare case in which a few of the enigmatic diffuse interstellar bands (DIBs) were convincingly assigned. $\mathrm{C}_{70}^{+}$is also expected to be present in space, but as a carrier of weaker DIBs (Campbell et al. 2016). Apart from the identification of these fullerenes themselves, their interstellar abundance (Campbell et al. 2016; Berné et al. 2017) also provides further support to the PAH hypothesis (Berné \& Tielens 2012), as facile interconversion between fullerenes and PAHs has been suggested upon hydrogenation of fullerenes or dehydrogenation of PAHs (Álvaro Galué 2014; Zhen et al. 2014).

Fullerenes can form derivatives, such as partially hydrogenated fullerenes, which have also been suggested to be present in the interstellar matter (ISM; Stoldt et al. 2001; Zhang et al. 2017, 2020; Díaz-Luis et al. 2018). However, the additional hydrogens in such species destabilize the carbon cage due to the change in orbital hybridization from $\mathrm{sp}^{2}$ to $\mathrm{sp}^{3}$ (Van Lier et al. 2002). In contrast,

Original content from this work may be used under the terms of the Creative Commons Attribution 4.0 licence. Any further distribution of this work must maintain attribution to the author(s) and the title of the work, journal citation and DOI. protonation does not affect the stability of the cage. Given on the one hand the high interstellar abundance of $\mathrm{H}^{+}$, and on the other hand the significant proton affinities $(\mathrm{PA})$ of $\mathrm{C}_{60}$ and $\mathrm{C}_{70}$ (around $860 \mathrm{~kJ} \mathrm{~mol}^{-1}$; McElvany \& Callahan 1991; Bohme 2009), protonated fullerenes were proposed as possibly abundant species in the ISM (Kroto \& Jura 1992).

$\mathrm{C}_{70}$ has been thoroughly characterized in neutral and ionic form and its ion chemistry and spectral features are well known (Taylor et al. 1990; Kato et al. 1991; Meilunas et al. 1991; Fulara et al. 1993; Zhou et al. 1996; Hedberg et al. 1997; von Helden et al. 1997; Schettino et al. 2002). Also, IR spectra are available for hydrogenated fullerenes (Iglesias-Groth et al. 2012). However, hardly any experimental spectroscopic data are available for protonated fullerenes, neither from gas-phase nor from condensed-phase (e.g., matrix isolation) experiments. The vibrational spectrum of $\mathrm{C}_{60} \mathrm{H}^{+}$was recently reported by our group (Palotás et al. 2020).

Protonation of fullerenes occurs through a $\sigma$-bond on one of the carbon atoms, similar to what was shown for protonation of PAHs (Solcà \& Dopfer 2002) and in contrast to the typical $\pi$ bonds formed between metal ions and aromatic molecules. Therefore, the addition of a proton breaks the five-fold rotation symmetry and reduces the symmetry of buckminsterfullerene $\mathrm{C}_{60}$ from $\mathrm{I}_{h}$ to $\mathrm{C}_{s}$. This major reduction of symmetry has severe implications for the spectroscopic selection rules and hence for the appearance of the spectrum. In $\mathrm{C}_{60}$, which has a very sparse IR spectrum, all vibrational normal modes become IR allowed upon protonation, resulting in a rich spectrum for $\mathrm{C}_{60} \mathrm{H}^{+}$ (Palotás et al. 2020).

In this Letter, we present the first experimental IR spectrum of $\mathrm{C}_{70} \mathrm{H}^{+}$in the gas phase. In contrast to $\mathrm{C}_{60}$, where all 60 carbon atoms are symmetrically identical, it is not immediately obvious where protonation is most likely to occur in $\mathrm{C}_{70}$ (Figure 1). Quantum-chemical calculations are necessary to explore the energetics of the different structures, and computed IR spectra for each of the isomers allow us to identify the species formed experimentally. Finally, the IR spectra of both 

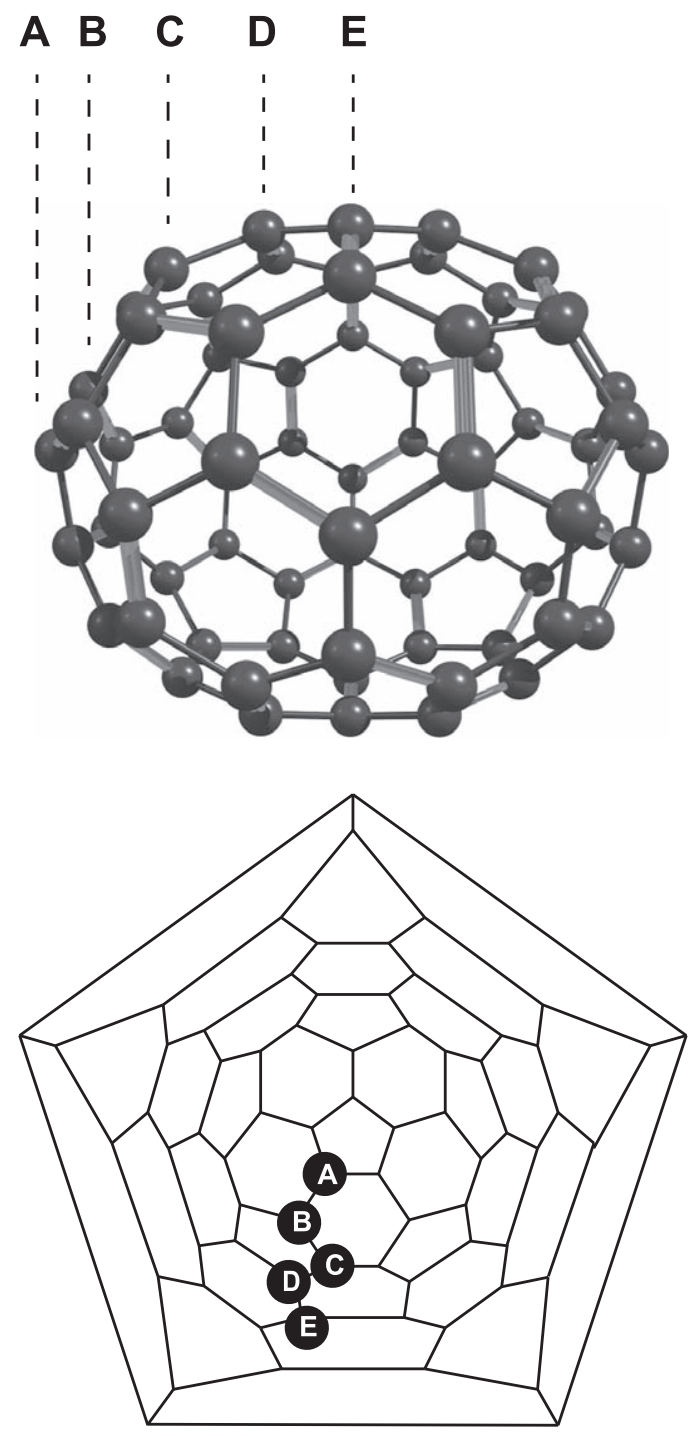

Figure 1. Structure of $\mathrm{C}_{70}$, as a 3D structure and as a Schlegel diagram, with the five distinct sites labeled A through $\mathrm{E}$.

protonated $\mathrm{C}_{60}$ and $\mathrm{C}_{70}$ are contrasted against emission spectra from fullerene-rich astronomical objects.

\section{Methods}

The gas-phase infrared multiple-photon dissociation (IRMPD) spectrum of $\mathrm{C}_{70} \mathrm{H}^{+}$ions was measured in a modified 3D quadrupole ion trap (Bruker Amazon Speed ETD) coupled to the Free-Electron Laser for Infrared eXperiments (FELIX; Martens et al. 2016). Protonated $\mathrm{C}_{70}$ was produced in an atmospheric pressure chemical ionization (APCI) source, which is particularly efficient for apolar molecules such as polycyclic aromatic hydrocarbons (Marvin et al. 1999; Grosse \& Letzel 2007) and fullerenes; it was used to produce protonated $\mathrm{C}_{60}$ in our previous study (Palotás et al. 2020). $\mathrm{C}_{70}(99+\%)$ powder was purchased from MER Corporation (USA) and dissolved in toluene to create a $1 \mathrm{mmol}$ stock solution, which was further diluted in a 50/50\% methanol-toluene mixture to reach a final concentration of about $10 \mu \mathrm{mol}$. The solution was introduced into the APCI source at a flow rate of $15 \mu \mathrm{l}$ minute ${ }^{-1}$, nebulized with nitrogen gas at $3.5 \mathrm{bar}$ and $270^{\circ} \mathrm{C}$, and desolvated at $450^{\circ} \mathrm{C}$. The corona current was
$6 \mu \mathrm{A}$, and the potential difference between the end plate and capillary was set to $4500 \mathrm{~V}$.

\subsection{IRMPD Spectroscopy}

The APCI source produces both the radical cation $\left(\mathrm{C}_{70}^{+}\right.$at $\mathrm{m} /$ $z$ 840) and the protonated species $\left(\mathrm{C}_{70} \mathrm{H}^{+}\right.$at $\left.m / z 841\right)$; see the inset of Figure 2. We isolate the ions at a nominal mass of 841 in the trap, knowing that due to the natural abundance of the ${ }^{13} \mathrm{C}$ carbon isotope, this peak must be a superposition of two ions: protonated ${ }^{12} \mathrm{C}_{70}$ and the radical cation of ${ }^{13} \mathrm{C}^{12} \mathrm{C}_{69}$. The mass resolution of the ion trap mass spectrometer is insufficient to resolve the two ions on the basis of their small mass difference. We observe that IR-induced dissociation of the ions at $\mathrm{m} / z 841$ produces fragments only in the $\mathrm{m} / z 840$ channel. The fact that only $\mathrm{H}$-atom loss is observed indicates that the irradiation employed in our experiments is not intense enough to destroy the carbon cage. Importantly, this allows us to spectroscopically sample exclusively the ${ }^{12} \mathrm{C}_{70} \mathrm{H}^{+}$ions in the presence of the co-isolated ${ }^{13} \mathrm{C}^{12} \mathrm{C}_{69}^{+}$ions (see also the inset in Figure 2). Irradiating the $\mathrm{m} / \mathrm{z} 841$ ion population using an increasing number of laser pulses leads to a nonzero plateau in the depletion curve, see Figure A1 in the Appendix, that indicates that approximately $45 \%$ of the isolated $\mathrm{m} / \mathrm{z} 841$ ion population is ${ }^{13} \mathrm{C}^{12} \mathrm{C}_{69}^{+}$.

An IR spectrum of ${ }^{12} \mathrm{C}_{70} \mathrm{H}^{+}$was thus obtained by irradiating the trapped $\mathrm{m} / \mathrm{z} 841$ ion cloud with the tunable IR light from FELIX. After irradiation, a mass spectrum of the contents of the trap is recorded (Oomens et al. 2006) and averaged six times. The wavelength is then tuned in steps of $3 \mathrm{~cm}^{-1}$ and the mass spectrometry (MS) sequence is repeated, so that an IRMPD spectrum can be reconstructed from the wavelengthdependent fragmentation of $\mathrm{m} / z 841$ into $\mathrm{m} / \mathrm{z}$ 840. Specifically, we monitor the fragmentation yield $Y(\lambda)$

$$
Y(\lambda)=\frac{I_{m 840}}{0.55 \cdot\left[I_{m 840}+I_{m 841}\right]},
$$

in which we have accounted for the contribution of the ${ }^{13} \mathrm{C}^{12} \mathrm{C}_{69}^{\cdot+}$ cation. The fragment fluence $(S(\lambda))$ is then calculated as (Berden et al. 2019)

$$
S(\lambda)=-\ln (1-Y) \text {. }
$$

$S(\lambda)$ was linearly corrected for variations of the laser pulse energy over the scan range and for the irradiation time.

IRMPD of large and stable carbonaceous ions is challenging due to their high dissociation threshold. Therefore, to assist the IRMPD process, the background helium pressure in the ion trapping region, which helps to trap the ions more efficiently, was reduced to its minimum value in order to reduce collisional quenching of the excitation induced by IR absorption (Martens et al. 2016). Despite the lower overall ion count, a better quality IRMPD spectrum is thus obtained.

FELIX produces macropulses at a $10 \mathrm{~Hz}$ repetition rate that are about $7 \mu \mathrm{s}$ long and that consist of a train of micropulses spaced by $1 \mathrm{~ns}$. The micropulses are Fourier transform limited and have a bandwidth of $0.4 \%$ of the IR frequency. The IR spectrum was recorded between 6 and $25 \mu \mathrm{m}$ and in this wavelength region, FELIX produces macropulse energies up to approximately $200 \mathrm{~mJ}$. The wavelength is calibrated with a grating spectrometer with an accuracy of $\pm 0.01 \mu \mathrm{m}$. 
Wavelength $(\mu \mathrm{m})$
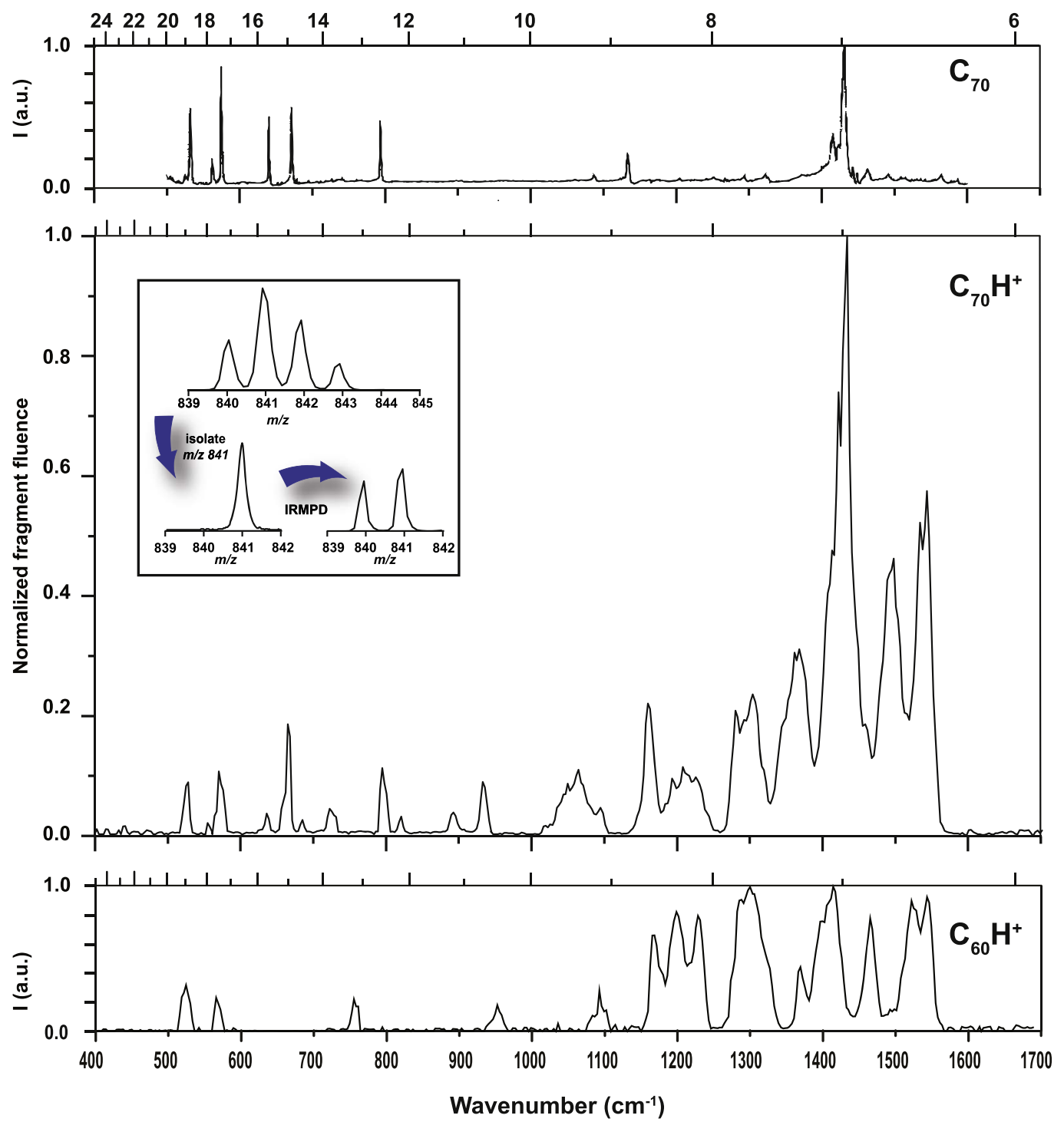

Figure 2. IRMPD spectrum of $\mathrm{C}_{70} \mathrm{H}^{+}$(middle) compared with a Fourier transform IR (FTIR) absorption spectrum of $\mathrm{C}_{70}$ (top) (Schettino et al. 2002) and with the IRMPD spectrum of $\mathrm{C}_{60} \mathrm{H}^{+}$(bottom). In the inset, details of the mass spectra are shown. Following the arrows, the mass spectrum of the sample as produced by the APCI source, the mass spectrum upon isolation of $m / z 841$, and the mass spectrum upon resonant IRMPD fragmentation.

\subsection{Quantum-chemical Computations}

Quantum-chemical calculations of the five $\mathrm{C}_{70} \mathrm{H}^{+}$isomers were performed using density functional theory (DFT) at the B3LYP $/ 6-311+\mathrm{G}(\mathrm{d}, \mathrm{p})$ level. At the B3LYP-optimized geometry, single-point calculations were performed at the M06-2X/6-311+G(d,p) and MP2/6-311+G(d,p) levels to obtain further benchmarks for the relative energies. Optimized geometries are included as machine-readable data files (see the Appendix). Vibrational spectra were computed within the harmonic oscillator approximation and computed frequencies were scaled by 0.978 . Calculated stick spectra were convoluted with a Gaussian line profile with an FWHM of $1 \%$ of the wavenumber. Band centers were determined from the convoluted spectra and contrasted against experimental band positions as shown in Table A1 in the Appendix. All calculations used the Gaussian16 software package at the Dutch national supercomputer Cartesius at SurfSARA.

\section{Results and Discussion}

Compared to $\mathrm{C}_{60}, \mathrm{C}_{70}$ has 10 additional carbon atoms, which are added in the form of a cylindrical belt. This ellipsoidal distortion lowers the symmetry from $I_{h}$ for $\mathrm{C}_{60}$ to $\mathrm{D}_{5 h}$ for $\mathrm{C}_{70}$. As a consequence, there are five nonequivalent carbon centers in the $\mathrm{C}_{70}$ cage, which give rise to five different isomers that can be formed upon (exohedral) protonation (see Figure 1). Note that endohedral protonation was ignored based on our study on protonated $\mathrm{C}_{60}$, which showed that endohedral protonation leads to a structure that is $193 \mathrm{~kJ} \mathrm{~mol}^{-1}$ higher in energy than the exohedrally protonated ion (Palotás et al. 2020). Computed relative energies for the five isomers of protonated $\mathrm{C}_{70}$ are listed in Table 1 and further discussed below.

\subsection{Vibrational Spectrum}

The IRMPD spectrum of $\mathrm{C}_{70} \mathrm{H}^{+}$is presented in Figure 2. A Fourier transform IR (FTIR) spectrum of $\mathrm{C}_{70}$ (Schettino et al. 2002) is shown for comparison, as well as the IRMPD 
Table 1

Relative Gibbs Free Energies of the Five Isomers of Protonated $\mathrm{C}_{70}$

\begin{tabular}{lcccc}
\hline \hline \multirow{2}{*}{ Protonation Site } & \multirow{2}{*}{ Point Group } & \multicolumn{3}{c}{ Gibbs Free Energy $\left(\mathrm{kJ} \mathrm{mol}^{-1}\right)$} \\
\cline { 3 - 5 } & & B3LYP & M06-2X & MP2 \\
\hline A & $\mathrm{C}_{s}$ & 21.3 & 22.3 & 51.2 \\
$\mathrm{~B}$ & $\mathrm{C}_{s}$ & 0.8 & 6.9 & 0 \\
$\mathrm{C}$ & $\mathrm{C}_{1}$ & 11.2 & 14.2 & 36.1 \\
$\mathrm{D}$ & $\mathrm{C}_{1}$ & 0 & 0 & 23.3 \\
E & $\mathrm{C}_{s}$ & 54.7 & 59.4 & 73.7 \\
\hline
\end{tabular}

Note. Optimization and frequency calculations were performed at the B3LYP/ $6-311+\mathrm{G}(\mathrm{d}, \mathrm{p})$ level. Entries in the last two columns correspond to single-point electronic energies, computed using M06-2X/6-311+G(d,p) and MP2/6-311 $+\mathrm{G}(\mathrm{d}, \mathrm{p})$ levels at the B3LYP-optimized geometry. Zero-point energy and thermal corrections were derived from the B3LYP frequency calculations and applied to all values listed.

spectrum of protonated $\mathrm{C}_{60}$ (Palotás et al. 2020). The $\mathrm{C}_{70} \mathrm{H}^{+}$ vibrational spectrum shares many characteristics with the spectrum of $\mathrm{C}_{60} \mathrm{H}^{+}$. It has its strongest bands between 1160 and $1570 \mathrm{~cm}^{-1}$; bands in this range correspond to $\mathrm{C}-\mathrm{C}$ stretching modes, some with partial $\mathrm{C}-\mathrm{H}$ bending character of the added proton. Clearly, the strongly reduced symmetry and the consequently relaxed selection rules as compared to $\mathrm{C}_{70}$, gives rise to a significantly larger number of vibrational bands in the spectrum of $\mathrm{C}_{70} \mathrm{H}^{+}$.

The strongest peak in both the $\mathrm{C}_{70}$ and $\mathrm{C}_{70} \mathrm{H}^{+}$spectra is due to $\mathrm{C}-\mathrm{C}$ stretching, and the most intense peak is at nearly the same frequency in the neutral and in the protonated system $\left(1434 \mathrm{~cm}^{-1}\right)$. Toward longer wavelengths, the $\mathrm{C}_{70}$ and $\mathrm{C}_{70} \mathrm{H}^{+}$ spectra show more similarity. The weak bands in this region are due to ring deformations and breathing modes. The narrow peaks in the spectrum of the protonated species are slightly redshifted but remain within approximately $10 \mathrm{~cm}^{-1}$ of their counterparts in the spectrum of the neutral molecule. For protonated $\mathrm{C}_{70}$, several additional peaks are observed at 723 , 821,893 , and $933 \mathrm{~cm}^{-1}$. Consistently, peaks between 700 and $1000 \mathrm{~cm}^{-1}$ are also present in the spectrum of $\mathrm{C}_{60} \mathrm{H}^{+}$, but absent in the $\mathrm{C}_{60}$ spectrum. Moreover, relative intensities of the $\mathrm{C}-\mathrm{C}$ stretch modes in the $1100-1600 \mathrm{~cm}^{-1}$ range are much lower in $\mathrm{C}_{70}$.

\subsection{Protonation Sites and Computed Spectra}

The symmetry of $\mathrm{C}_{70} \mathrm{H}^{+}$depends on the site of protonation, so that the isomers belong either to the $\mathrm{C}_{s}$ or to the $\mathrm{C}_{1}$ point group. The $\mathrm{C}_{s}$ symmetry isomers have one remaining mirror plane as a symmetry element. In both cases, all vibrational modes become symmetry allowed, which changes the IR spectrum drastically as compared to that of $\mathrm{C}_{70}$.

Theoretical investigations on the hydrogenation of $\mathrm{C}_{70}$ have been reported (Sun et al. 2009; Tokunaga et al. 2011) and suggest that structure $A$ is the most stable isomer of the $\mathrm{C}_{70} \mathrm{H}$ radical. However, to the best of our knowledge, no investigations of the preferred protonation isomer have been reported to date. Here, we choose to employ the hybrid B3LYP density functional, which has been shown to give reliable predicted IR spectra (Katari et al. 2017), specifically also for polyaromatic molecules (Bauschlicher et al. 2018) and protonated $\mathrm{C}_{60}$ (Palotás et al. 2020). In contrast to the $\mathrm{C}_{70} \mathrm{H}$ radical, structures $\mathrm{B}$ and $\mathrm{D}$ are computed to be lowest-energy isomers for $\mathrm{C}_{70} \mathrm{H}^{+}$. These isomers are virtually isoenergetic and are at least

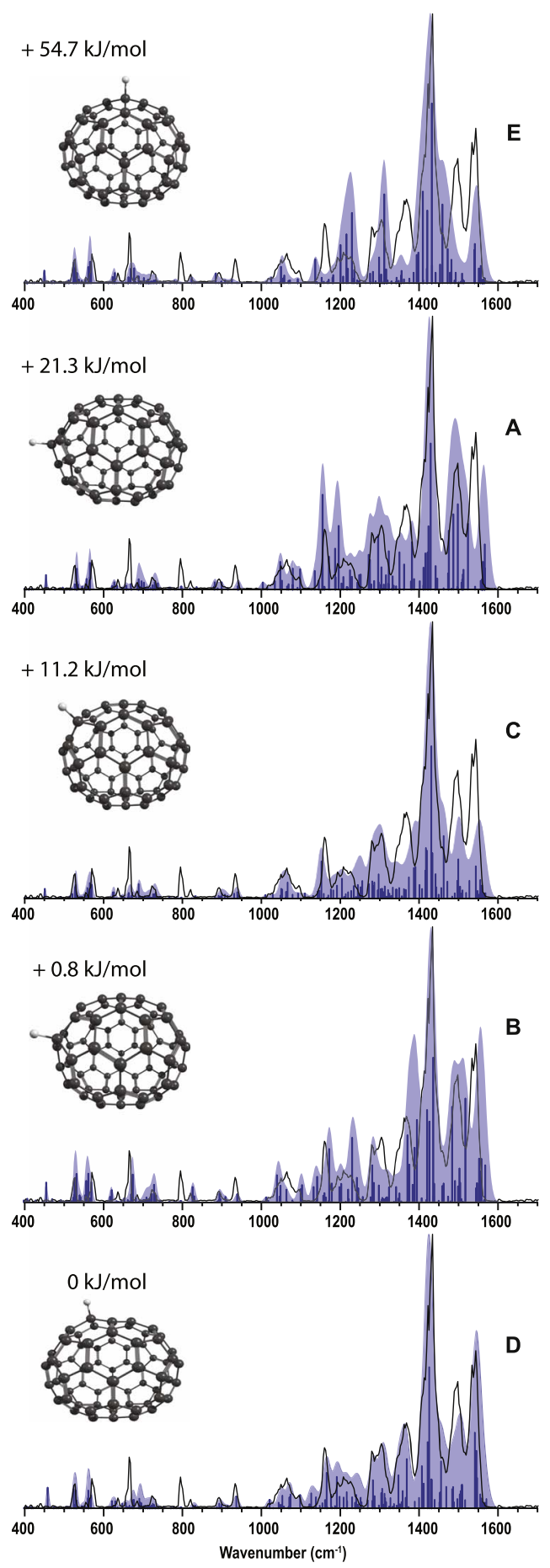

Figure 3. IRMPD spectrum of $\mathrm{C}_{70} \mathrm{H}^{+}$(black, all panels) compared to computed spectra (blue) of the five isomers obtained by protonation at carbon atoms A through $\mathrm{E}$ in Figure 1. Geometry optimizations and harmonic frequency calculations are performed at the B3LYP/6-311+G(d,p) level and relative Gibbs energies at that level of theory are shown. Band centers after convolution with a Gaussian line profile are listed in Table A2 in the Appendix, along with rms deviations from experimental band centers.

$10 \mathrm{~kJ} \mathrm{~mol}^{-1}$ lower in energy than the other isomers. Despite the comparable energies of $\mathrm{B}$ and $\mathrm{D}$, their computed spectra show subtle differences and it is the computed spectrum of $\mathrm{D}$ that matches the experimental spectrum of $\mathrm{C}_{70} \mathrm{H}^{+}$most closely (see Figure 3), especially in the short wavelength region from 900 to $1600 \mathrm{~cm}^{-1}$. 
Despite the reliable IR spectra provided by the B3LYP functional, methods that better account for dispersion interactions, such as the M06-2X density functional or Møller-Plesset perturbation theory (MP2), are believed to outperform B3LYP in the prediction of electronic energies. Single-point calculations using these methods were therefore performed at the B3LYP-optimized geometry. In Table 1, we list the relative Gibbs free energies, using for all values the zero-point energy and thermal corrections from the B3LYP calculation. The energetic ordering of isomers at the M06-2X level is the same as at the B3LYP level, although M06-2X places the global minimum structure $\mathrm{D}$ approximately 5 $\mathrm{kJ} \mathrm{mol}^{-1}$ lower relative to the other isomers. At the MP2 level, structure B is lowest in energy, with structure D significantly higher at $23 \mathrm{~kJ} \mathrm{~mol}^{-1}$. This appears in contrast with the optimum spectral match with isomer D (see Figure 3 and the rms deviations in Table A1) and leads us to conclude that the MP2 energies are not accurate in this case and may require a geometry optimization at this level, which is beyond our computational resources. M06-2X favors structure D more prominently over $\mathrm{B}$, which is indeed what the IR spectrum appears to suggest. However, we cannot exclude a minor contribution from $\mathrm{B}$ : assuming that the isomers are in thermal equilibrium at room temperature, M06-2X gives Boltzmann fractions of 0.06:0.94 for $\mathrm{B}: \mathrm{D}$, versus $0.42: 0.57$ for B3LYP; synthetic spectra for these two ratios of isomers show only subtle variations and are contrasted against the experimental spectrum in Figure A2 in the Appendix.

The experimental spectrum shows a peculiar band at $795 \mathrm{~cm}^{-1}$, which is not reproduced by the frequency calculations for any of the isomers (see Figure 3). We relate this observation to earlier studies reporting FTIR spectra of $\mathrm{C}_{70}$ (Bethune et al. 1991; Meilunas et al. 1991), which also show this feature that is also not reproduced in theoretical spectra of $\mathrm{C}_{70}$ (Bakowies \& Thiel 1991; Jishi et al. 1993; Stratmann et al. 1998). It has been suggested that the band is due to a contamination in the sample, but based on the present, mass-selective IR spectrum, this hypothesis can be dismissed (assuming the band has the same origin in $\mathrm{C}_{70}$ and $\mathrm{C}_{70} \mathrm{H}^{+}$). Stratmann et al. (1998) proposed that the peak originates from anharmonicity. We presume that the band at $795 \mathrm{~cm}^{-1}$ in $\mathrm{C}_{70} \mathrm{H}^{+}$is due to an exceptionally strong overtone or combination mode. An anharmonic vibrational analysis has not been performed because of the excessive computational cost for molecules of this size.

$\mathrm{C}_{70} \mathrm{H}^{+}$possesses a single $\mathrm{C}-\mathrm{H}$ stretch mode. The computed spectrum of isomer D places the band at $2848 \mathrm{~cm}^{-1}$ - using a scaling factor of 0.9610 (Palotás et al. 2020)—with a computed intensity of $22 \mathrm{~km} \mathrm{~mol}^{-1}$. However, similar to our experience with $\mathrm{C}_{60} \mathrm{H}^{+}$, we were unable to detect this band experimentally, likely due to the 10 times lower laser power available in this spectral region (using both FELIX and a benchtop laser system) in combination with the low integrated intensity and the isolated nature of this band.

\subsection{Astrophysical Implications}

The emission spectrum from the SMP LMC56 planetary nebula is arguably one of the cleanest fullerene-containing nebulae found. The observed spectrum is largely devoid of the main PAH emission features and the bands of $\mathrm{C}_{60}$ are clearly observed, as well as traces of $C_{70}$ (Bernard-Salas et al. 2012).
We therefore compare our experimental spectrum of $\mathrm{C}_{70} \mathrm{H}^{+}$ against this astronomical emission spectrum in Figure 4.

There is no consensus in literature about the origin of the $6-9 \mu \mathrm{m}$ plateau, which has been detected in other planetary nebulae as well (Bernard-Salas et al. 2012). It has been proposed that this feature may be due to hydrogenated amorphous carbon (HAC) grains and fullerenes formed in their decomposition (García-Hernández et al. 2010). On the other hand, it has also been attributed to large PAH clusters or carbonaceous grains (Stanghellini et al. 2007).

As an alternative, we suggest that the $6-9 \mu \mathrm{m}$ plateau may be due to a mix of neutral, ionized, and protonated fullerenes. Focusing on the most abundant fullerenes $\mathrm{C}_{60}$ and $\mathrm{C}_{70}$, it is clear that the plateau cannot be solely due to the neutral molecules, which have very sparse IR spectra; note that the two $\mathrm{C}_{60}$ bands in this range are prominently observed on top of the plateau. In Figure 4 , we investigate whether protonated $\mathrm{C}_{60}$ and $\mathrm{C}_{70}$, which feature a significant number of (partially unresolved) bands in this region, may be able to fill up much of the plateau. To construct Figure 4(b), we used a 1:5 ratio of $\mathrm{C}_{70} \mathrm{H}^{+}$and $\mathrm{C}_{60} \mathrm{H}^{+}$, which corresponds to the highest reachable $\mathrm{C}_{70} / \mathrm{C}_{60}$ ratio in laboratory arc reactors (Krätschmer et al. 1990; Taylor \& Walton 1993); both the higher proton affinity and total spectral intensity (see Table A2 in the Appendix for computed values) may slightly increase the contribution of $\mathrm{C}_{70} \mathrm{H}^{+}$relative to that of $\mathrm{C}_{60} \mathrm{H}^{+}$. Clearly, the spectra of the two fullerenes and their protonated forms cannot account for all spectral features observed in the astronomical spectrum, so that other species must be present if this hypothesis is correct. Obvious candidates are the radical cations $\mathrm{C}_{60}^{+}$and $\mathrm{C}_{70}^{+}$. A gas-phase IR spectrum for $\mathrm{C}_{60}^{+}$tagged with one or more $\mathrm{He}$ atom has been reported recently (Gerlich et al. 2018), though without interpretation based on DFT calculations so that the influence of the (symmetrybreaking) He tag on the spectrum remains unclear. Vice versa, computational spectra for various ionic fullerenes have been reported (Candian et al. 2019), but without experimental verification thus far.

The two bands between 17 and $20 \mu \mathrm{m}$ in the astronomical spectrum overlap with bands in the laboratory spectra of $\mathrm{C}_{60} \mathrm{H}^{+}$and $\mathrm{C}_{70} \mathrm{H}^{+}$as well as with pronounced bands in $\mathrm{C}_{60}$ and $\mathrm{C}_{70}$. The broadening observed in the astronomical spectra of these peaks at 17.3 and $18.9 \mu \mathrm{m}$ may then be a consequence of the combined emission from various fullerene related species.

\section{Summary}

We reported the first gas-phase IR spectrum of protonated $\mathrm{C}_{70}$. As compared to $\mathrm{C}_{70}$, symmetry breaking upon addition of a proton leads to the appearance of a wealth of new peaks. We contrast the experimental spectrum to DFT-computed spectra of the five possible exohedral $\mathrm{C}_{70} \mathrm{H}^{+}$isomers, which leads us to conclude that the ion population formed under our experimental conditions likely contains only a single isomer: structure D in Figure 1. This structure corresponds to the lowest-energy isomer at the DFT level of theory. A composite spectrum constructed from the IR spectra of protonated $\mathrm{C}_{60}$ and $\mathrm{C}_{70}$ was compared to the emission spectrum from the SMP LMC56 planetary nebulae. We conclude that a mixture of $\mathrm{C}_{60} \mathrm{H}^{+}$and $\mathrm{C}_{70} \mathrm{H}^{+}$may indeed contribute to the emission spectra observed and could in particular explain much of the 
a)
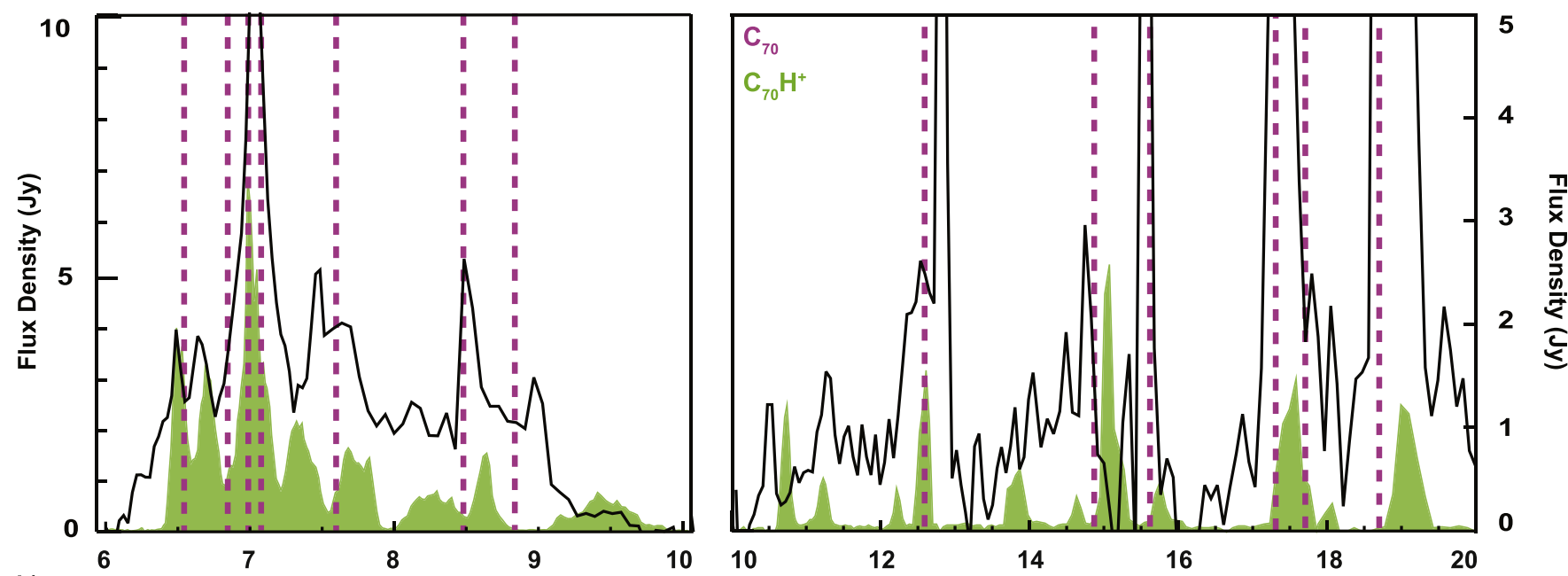

b)

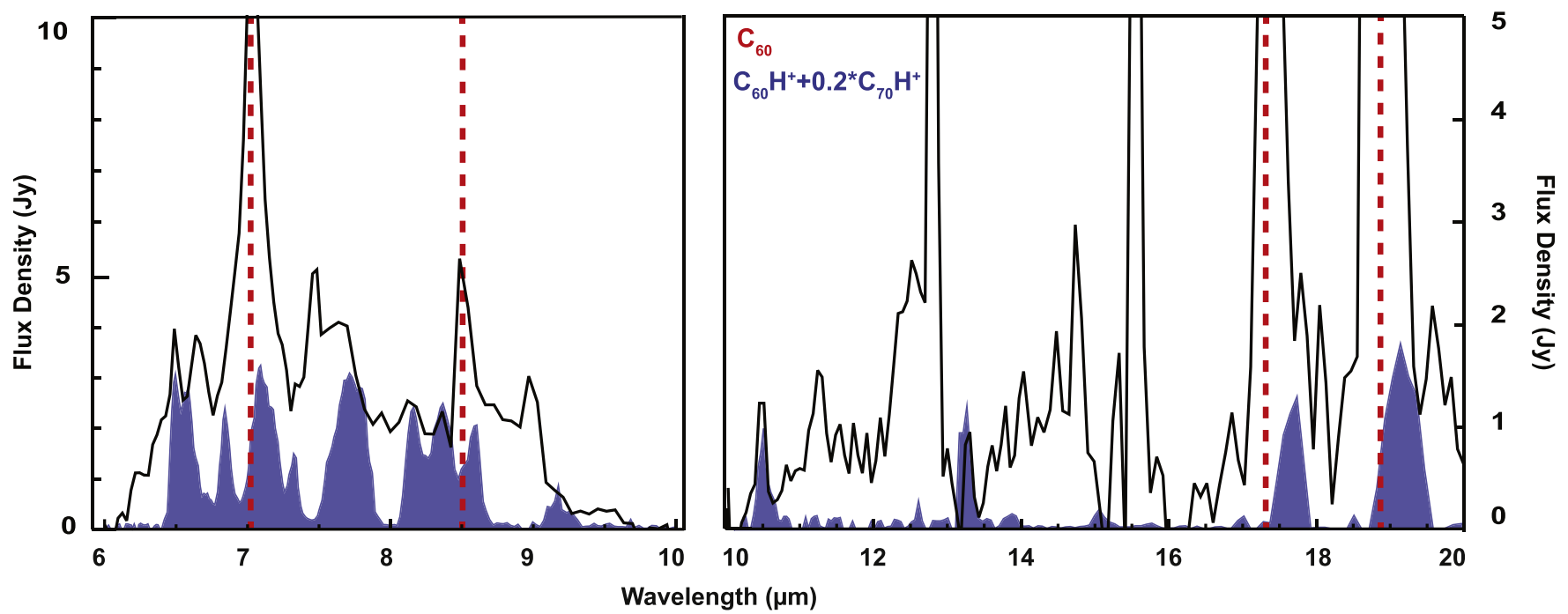

Figure 4. The experimental IR spectrum of $\mathrm{C}_{70} \mathrm{H}^{+}$(green) and a composite spectrum containing a 5-to-1 mixture of the spectra of $\mathrm{C}_{60} \mathrm{H}^{+}$and $\mathrm{C}_{70} \mathrm{H}^{+}$(blue) compared with the emission spectrum of SMP LMC56 (black) observed with the Spitzer Infrared Spectrograph (Bernard-Salas et al. 2012). Dashed lines indicate the positions of the $\mathrm{C}_{70}$ bands (pink, left) at $6.5,6.8,7.0,7.1,7.6,8.5,8.8,12.6,14.9,15.6,17.3,17.7$, and $18.7 \mu \mathrm{m}$ and the $\mathrm{C}_{60}$ bands (red, right) at 7.0, 8.5, 17.3, and 18.9 $\mu \mathrm{m}$.

emission in the 6-10 $\mu \mathrm{m}$ range; no bands are observed for $\mathrm{C}_{60} \mathrm{H}^{+}$and $\mathrm{C}_{70} \mathrm{H}^{+}$that would conflict with the astronomical spectra.

We gratefully acknowledge the Nederlandse Organisatie voor Wetenschappelijk Onderzoek (NWO) for the support of the FELIX laboratory. This work is supported by the European MCSA ITN network "EUROPAH" (grant No. 722346) and the Dutch Astrochemistry Network (DAN-II, grant No. 648.000.030) of NWO. For the computational work, we acknowledge support by NWO Exact and Natural Sciences under the "Rekentijd" program (grant No. 2019.062) and the SurfSARA staff.

\section{Appendix}

Additional experimental and computational data on several aspects of the study are provided. Figure A1 shows an experiment to determine the ratio $12 \mathrm{C} 70 \mathrm{H}+/ 13 \mathrm{C} 12 \mathrm{C} 69+$ in the trap. Figure A2 compares composite computed spectra to the experimental data. Table A1 lists IR band centers for the different $\mathrm{C} 70 \mathrm{H}+$ isomers. Table A2 lists additional computed properties for the species under study, including proton affinities, $\mathrm{CH}$ stretch frequencies and total integrated band intensities. Optimized geometries computed at the B3LYP/6$311+\mathrm{G}(\mathrm{d}, \mathrm{p})$ level of theory for isomers A through $\mathrm{E}$ are available inmachine-readable format with xyz-atom positions listed in $\AA$. Abrief sample of the data is shown in Table A3. 


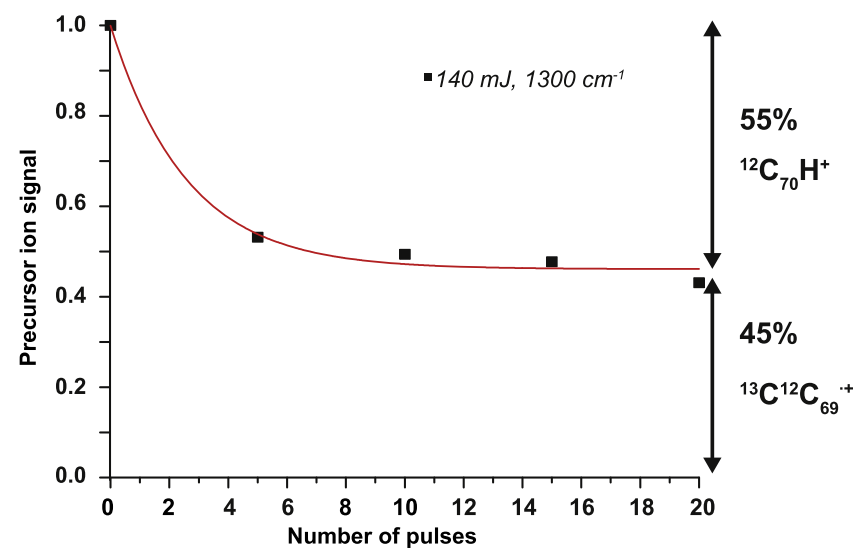

Figure A1. Depletion of the $m / z, 841$ ion population at a laser frequency of $1300 \mathrm{~cm}^{-1}$ as function of the number of laser pulses. At this frequency, $\mathrm{C}_{70} \mathrm{H}^{+}$absorbs and fragments from $\mathrm{m} / \mathrm{z} 841$ to $\mathrm{m} / \mathrm{z}$ 840. Increasing the number of pulses leads to a plateau in the depletion that indicates that approximately $45 \%$ of the isolated ion population at $m / z 841$ is ${ }^{13} \mathrm{C}^{12} \mathrm{C}_{69}^{+}$, which cannot be fragmented under our experimental conditions. The red line is a single-exponential fit to the data points.
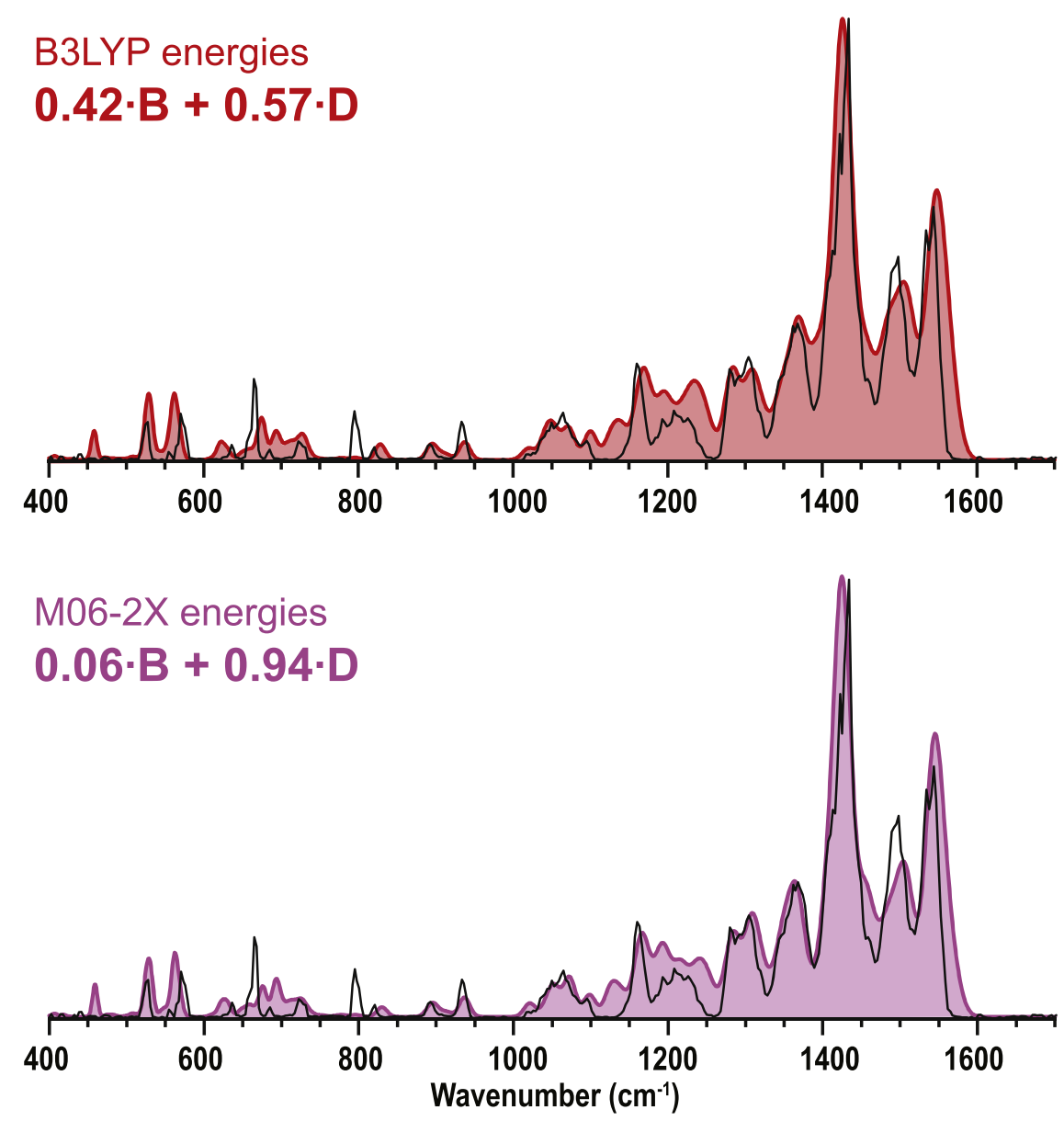

Figure A2. The experimental spectrum for $\mathrm{C}_{70} \mathrm{H}^{+}$compared against a synthetic spectrum corresponding to the weighted average of the computed spectra of isomers $\mathrm{B}$ and D. The weighing factors are the Boltzmann fractions at room temperature according to the relative free energies at the B3LYP (top) and M06-2X (bottom) level of theory. Boltzmann fractions for the other isomers are negligible. 
Table A1

Band Centers in $\mathrm{cm}^{-1}$ from the Experimental Spectrum and from the Convoluted Theoretical Spectra of Isomers A through E

\begin{tabular}{|c|c|c|c|c|c|c|c|c|c|c|}
\hline \multirow{2}{*}{ Exp } & \multicolumn{10}{|c|}{ Computed } \\
\hline & $\mathrm{A}$ & $\Delta$ & B & $\Delta$ & $\mathrm{C}$ & $\Delta$ & $\mathrm{D}$ & $\Delta$ & $\mathrm{E}$ & $\Delta$ \\
\hline$\overline{528}$ & 532.0 & 4.0 & 529.1 & 1.1 & 529.1 & 1.1 & 527.1 & 0.9 & 526.2 & $\overline{1.8}$ \\
\hline 570 & 565.3 & 4.7 & 559.4 & 10.6 & 565.3 & 4.7 & 561.4 & 8.6 & 565.3 & 4.7 \\
\hline 636 & 626.9 & 9.1 & 620.1 & 15.9 & 624.9 & 11.1 & 625.9 & 10.1 & 626.9 & 9.1 \\
\hline 665 & 657.2 & 7.8 & 672.9 & 7.9 & 667.0 & 2.0 & 675.8 & 10.8 & 669.0 & 4.0 \\
\hline 685 & 690.5 & 5.5 & $\ldots$ & $\ldots$ & 689.5 & 4.5 & 692.4 & 7.4 & $\ldots$ & $\ldots$ \\
\hline 723 & 730.6 & 7.6 & 727.6 & 4.6 & 729.6 & 6.6 & 722.7 & 0.3 & 728.6 & 5.6 \\
\hline 795 & 797.1 & 2.1 & $\ldots$ & $\ldots$ & $\ldots$ & $\ldots$ & $\ldots$ & $\ldots$ & $\ldots$ & $\ldots$ \\
\hline 821 & $\ldots$ & $\ldots$ & 826.4 & 5.4 & $\ldots$ & $\ldots$ & 829.3 & 8.3 & 823.5 & 2.5 \\
\hline 893 & 882.2 & 10.8 & 894.9 & 1.9 & 899.8 & 6.8 & 895.8 & 2.8 & 884.1 & 8.9 \\
\hline 933 & 941.8 & 8.8 & 938.9 & 5.9 & 936.9 & 3.9 & 935.9 & 2.9 & $\ldots$ & $\ldots$ \\
\hline 1065 & 1048.4 & 16.6 & 1043.5 & 21.5 & 1060.2 & 4.8 & 1071.9 & 6.9 & 1052.3 & 12.7 \\
\hline 1160 & 1156.0 & 4.0 & 1172.6 & 12.6 & 1151.1 & 8.9 & 1165.8 & 5.8 & 1137.4 & 22.6 \\
\hline 1208 & 1193.2 & 14.8 & 1232.3 & 24.3 & 1202.9 & 5.1 & 1192.2 & 15.8 & 1226.4 & 18.4 \\
\hline 1304 & 1298.8 & 5.2 & 1283.1 & 20.9 & 1299.8 & 4.2 & 1308.6 & 4.6 & 1310.5 & 6.5 \\
\hline 1368 & 1381.9 & 13.9 & 1389.7 & 21.7 & 1389.7 & 21.7 & 1362.4 & 5.6 & 1354.5 & 13.5 \\
\hline 1434 & 1425.9 & 8.1 & 1429.8 & 4.2 & 1427.9 & 6.1 & 1424.9 & 9.1 & 1427.9 & 6.1 \\
\hline 1498 & 1491.5 & 6.5 & 1510.0 & 12.0 & 1500.3 & 2.3 & 1504.2 & 6.2 & $\ldots$ & $\ldots$ \\
\hline 1543 & 1563.8 & 20.8 & 1556.0 & 13.0 & 1552.1 & 9.1 & 1545.2 & 2.2 & 1545.2 & 2.2 \\
\hline RMSD & & 10.06 & & 13.63 & & 8.00 & & 7.48 & & 10.34 \\
\hline
\end{tabular}

Note. Deviations between experimental and calculated values $(\Delta)$ and the root mean square deviations (RMSD) are also listed, showing that isomer D provides the best match. Harmonic frequencies are calculated at the B3LYP/6-311+G(d,p) level and scaled by 0.980 .

Table A2

Total Integrated Intensities of All Vibrational Bands of $\mathrm{C}_{60} \mathrm{H}^{+}$, the Five Isomers of $\mathrm{C}_{70} \mathrm{H}^{+}, \mathrm{C}_{60}$, and $\mathrm{C}_{70}$ and the Proton Affinities of $\mathrm{C}_{60}$ and $\mathrm{C}_{70}$ as Computed at the B3LYP/6-311+G(d,p) Level of Theory

\begin{tabular}{lcccc}
\hline \hline & $\begin{array}{c}\text { Total Integrated } \\
\text { Intensity } \\
\left(\mathrm{km} \mathrm{mol}^{-1}\right)\end{array}$ & $\begin{array}{c}\text { Proton } \\
\text { Affinity } \\
\left(\mathrm{kJ} \mathrm{mol}^{-1}\right)\end{array}$ & $\begin{array}{c}\text { C-H Stretch Band } \\
\text { Position } \\
\left(\mathrm{cm}^{-1}\right)\end{array}$ \\
\hline $\mathrm{C}_{60} \mathrm{H}^{+}$ & $\mathrm{A}$ & 790 & 855 & 2850.4 \\
& $\mathrm{~B}$ & 701 & 850 & 2847.0 \\
$\mathrm{C}_{70} \mathrm{H}^{+}$ & $\mathrm{C}$ & 992 & 870 & 2852.7 \\
& $\mathrm{D}$ & 876 & 860 & 2842.4 \\
$\mathrm{C}_{60}$ & $\mathrm{E}$ & 907 & 872 & 2848.1 \\
$\mathrm{C}_{70}$ & & 215 & 817 & 2801.5 \\
\hline
\end{tabular}

Note. The band centers of the $\mathrm{C}-\mathrm{H}$ stretch are also listed for the protonated species. Harmonic frequencies are scaled by 0.961 (Palotás et al. 2020)

Table A3

\begin{tabular}{lcccc}
\hline \hline Isomer & Atom & $\mathrm{X}(\AA)$ & $\mathrm{Y}(\AA)$ & $\mathrm{Z}(\AA)$ \\
\hline $\mathrm{A}$ & $\mathrm{C}$ & -4.173250 & -1.268262 & -0.000303 \\
$\mathrm{~A}$ & $\mathrm{C}$ & -3.959863 & -0.325567 & -1.184868 \\
$\mathrm{~A}$ & $\mathrm{C}$ & -3.940650 & 1.02995 & -0.725123 \\
$\mathrm{~A}$ & $\mathrm{C}$ & -3.940689 & 1.029686 & 0.725165 \\
$\mathrm{~A}$ & $\mathrm{C}$ & -3.959565 & -0.326021 & 1.184501 \\
$\cdots$ & $\cdots$ & $\cdots$ & $\cdots$ & $\cdots$ \\
\hline
\end{tabular}

(This table is available in its entirety in machine-readable form.)

\section{ORCID iDs}

Jonathan Martens (iD https://orcid.org/0000-0001-9537-4117

Giel Berden (1D https://orcid.org/0000-0003-1500-922X

Jos Oomens (D) https://orcid.org/0000-0002-2717-1278

\section{References}

Álvaro Galué, H. 2014, Chem. Sci., 5, 2667

Bakowies, D., \& Thiel, W. 1991, CP, 151, 309

Bauschlicher, C. W., Ricca, A., Boersma, C., \& Allamandola, L. J. 2018, ApJS, 234, 32

Berden, G., Derksen, M., Houthuijs, K. J., Martens, J., \& Oomens, J. 2019, IJMSp, 443, 1

Bernard-Salas, J., Cami, J., Peeters, E., et al. 2012, ApJ, 757, 41

Berné, O., Cox, N. L. J., Mulas, G., \& Joblin, C. 2017, A\&A, 605, L1

Berné, O., \& Tielens, A. G. G. M. 2012, PNAS, 109, 401

Bethune, D. S., Meijer, G., Tang, W. C., et al. 1991, CPL, 179, 181

Bohme, D. K. 2009, MSRv, 28, 672

Cami, J., Bernard-Salas, J., Peeters, E., \& Malek, S. E. 2010, Sci, 329, 1180

Campbell, E. K., Holz, M., Gerlich, D., \& Maier, J. P. 2015, Natur, 523, 322

Campbell, E. K., Holz, M., Maier, J. P., et al. 2016, ApJ, 822, 17

Candian, A., Gomes Rachid, M., MacIsaac, H., et al. 2019, MNRAS, 485,1137

Díaz-Luis, J. J., García-Hernández, D. A., Manchado, A., et al. 2018, AJ, 155,105

Ehrenfreund, P., \& Foing, B. 1997, AdSpR, 19, 1033

Fowler, P. W. 1996, ConPh, 37, 235

Fulara, J., Jakobi, M., \& Maier, J. P. 1993, CPL, 206, 203

García-Hernández, D. A., Iglesias-Groth, S., Acosta-Pulido, J. A., et al. 2011, ApJL, 737, L30

García-Hernández, D. A., Manchado, A., García-Lario, P., et al. 2010, ApJL, 724, L39

García-Hernández, D. A., Villaver, E., García-Lario, P., et al. 2012, ApJ, 760, 107

Gerlich, D., Jašík, J., Strelnikov, D. V., \& Roithová, J. 2018, ApJ, 864, 62

Grosse, S., \& Letzel, T. 2007, JChA, 1139, 75

Hedberg, K., Hedberg, L., Bühl, M., et al. 1997, JAChS, 119, 5314

Iglesias-Groth, S. 2019, MNRAS, 489, 1509

Iglesias-Groth, S., García-Hernández, D., Cataldo, F., \& Manchado, A. 2012, MNRAS, 423, 2868

Jishi, R., Dresselhaus, M., Dresselhaus, G., et al. 1993, CPL, 206, 187

Katari, M., Nicol, E., Steinmetz, V., et al. 2017, CEJ, 23, 8414

Kato, T., Kodama, T., Shida, T., et al. 1991, CPL, 180, 446

Krätschmer, W., Lamb, L., Fostiropoulos, K., \& Huffman, D. R. 1990, Natur, 347,354

Kroto, H. W. 1987, Natur, 329, 529

Kroto, H. W., Heath, J. R., O'Brien, S. C., Curl, R. F., \& Smalley, R. E. 1985, Natur, 318, 162

Kroto, H. W., \& Jura, M. 1992, A\&A, 263, 275 
Martens, J., Berden, G., Gebhardt, C. R., \& Oomens, J. 2016, RScI, 87, 103108

Marvin, C. H., Smith, R. W., Bryant, D. W., \& McCarry, B. E. 1999, JChA, 863,13

McElvany, S. W., \& Callahan, J. H. 1991, JPhCh, 95, 6186

Meilunas, R., Chang, R. P. H., Liu, S., Jensen, M., \& Kappes, M. M. 1991, JAP, 70, 5128

Oomens, J., Sartakov, B. G., Meijer, G., \& von Helden, G. 2006, IJMSp, 254, 1

Palotás, J., Martens, J., Berden, G., \& Oomens, J. 2020, NatAs, 4, 240

Schettino, V., Pagliai, M., \& Cardini, G. 2002, JPCA, 106, 1815

Sellgren, K., Werner, M. W., Ingalls, J. G., et al. 2010, ApJL, 722, L54

Solcà, N., \& Dopfer, O. 2002, Angew. Chem., 41, 3628

Stanghellini, L., García-Lario, P., García-Hernández, D. A., et al. 2007, ApJ, 671,1669

Stoldt, C. R., Maboudian, R., \& Carraro, C. 2001, ApJL, 548, L225
Stratmann, R. E., Scuseria, G. E., \& Frisch, M. J. 1998, JRSp, 29, 483

Sun, S., Sun, J., Hao, C., \& Li, S. 2009, JMoSt, 901, 66

Taylor, R., Hare, J. P., Abdul-Sada, A. K., \& Kroto, H. W. 1990, J. Chem. Soc., Chem. Commun., 1423

Taylor, R., \& Walton, D. R. M. 1993, Natur, 363, 685

Tokunaga, K., Ohmori, S., \& Kawabata, H. 2011, Mol. Cryst. Liq. Cryst., 539,252

Van Lier, G., De Proft, F., \& Geerlings, P. 2002, CPL, 366, 311

von Helden, G., Holleman, I., Knippels, G. M. H., van der Meer, A. F. G., \& Meijer, G. 1997, PhRvL, 79, 5234

Zhang, Y., Sadjadi, S., \& Hsia, C.-H. 2020, Ap\&SS, 365, 67

Zhang, Y., Sadjadi, S., Hsia, C.-H., \& Kwok, S. 2017, ApJ, 845, 76

Zhen, J., Castellanos, P., Paardekooper, D. M., Linnartz, H., \& Tielens, A. G. G. M. 2014, ApJL, 797, L30

Zhou, W., Xie, S., Qian, S., et al. 1996, JAP, 80, 459 